\title{
REFLEXÕES SOBRE OS PARADIGMAS BASEADOS NO CONHECIMENTO DO SENSO COMUM E CIENTÍFICO
}

\section{ARTIGO ORIGINAL}

ANTUNES, Maria De Fatima Nunes ${ }^{1}$

GUGLIELMI, Juçara ${ }^{2}$

ARCARI, Inedio ${ }^{3}$

ANTUNES, Maria De Fatima Nunes. GUGLIELMI, Juçara. ARCARI, Inedio. Reflexões sobre os paradigmas baseados no conhecimento do senso comum e científico. Revista Científica Multidisciplinar Núcleo do Conhecimento. Ano 05, Ed. 08, Vol. 05, pp. 57-63. Agosto de 2020. ISSN: 2448-0959, Link de acesso: https://www.nucleodoconhecimento.com.br/educacao/conhecimento-dosenso

\section{RESUMO}

$\mathrm{Na}$ educação de um país são fundadas as primeiras bases da reflexão sobre paradigmas, sendo esta a primeira base de reflexão que extrapola as convicções da família. O estudante é então exposto a uma grande variedade de verdades, afirmações de diferentes culturas e modos de vida. Logo, com este artigo pretende tecer algumas reflexões sobre os paradigmas relacionados ao senso comum e a ciência, discutindo aspectos voltados ao ambiente vivenciado por professores e alunos de acordo com a literatura. $O$ estudo baseou-se em uma pesquisa bibliográfica entrelaçando e discutindo a questão dos paradigmas, que no dia a dia da sala de aula são presenciados. Concluiu-se nessas reflexões que o modo tradicional de se

\footnotetext{
${ }^{1}$ Mestra em Ensino de Ciências Exatas. Pedagoga.

${ }^{2}$ Mestranda em Ensino de Ciências Exatas. Pedagoga.

${ }^{3}$ Doutor em Engenharia Elétrica e Mestre em Matemática.
} 
apresentar a educação envolto de paradigmas, passa por algumas discussões que aos poucos tem provocado uma ruptura neste modo de educação, reconstruindo assim, novos paradigmas.

Palavras-chave: Senso Comum, paradigmas, verdades, educação.

\section{INTRODUÇÃO}

Quando fala-se em mudança na educação, parece ser algo muito simples, mas ao resgatar a história da educação percebe-se que não é tão fácil assim mudar pensamentos, valores, crenças de um povo, pois a maioria dos envolvidos acredita nos saberes de uma comunidade, assim como entendido por Alves (2005) ao afirmar que, mesmo preferindo não definir, ele simplesmente diz que o senso comum é aquilo não é considerado ciência, e isso inclui todas os feitos do dia-a-dia, bem como as ideias e esperanças que sobrepõem a vida.

Desta forma, o senso comum funciona muito bem para se viver em família, principalmente quando se trata de valores e cultura de um determinado grupo da sociedade, pois cada pessoa tem sua convicção sobre determinado conceito. Porém é discutível a existência de uma verdade pronta e acabada, pois está vulnerável às constantes transformações de um determinado conceito, de um ponto de vista particular.

Trazendo para a realidade da sala de aula, os estudantes interrogam e discutem os mais diversos tipos de conhecimento vivenciados em seu cotidiano. Partem de suas imaginações, aspectos fundamentais para a construção de um conhecimento que ainda não é uma verdade consolidada. Não é salutar ao professor abordar seus ideais e impô-los para que sobreponham os pensamentos dos estudantes, pois a imposição pode induzi-lo a não ser reflexivo, autônomo e crítico. Sobre o conceito de verdade Foucault (1979) diz que nem tudo possui a verdade absoluta, mas a todo momento e lugar existe uma verdade que precisa ser descoberta, no entanto ela só está ali adormecida, esperando alguém desvendá-la. Todavia cabe a nós identificá-la da 
maneira certa com instrumentos e ângulos corretos, pois de qualquer modo ela está presente em algum lugar.

Partindo da premissa que nem todo o conhecimento é uma verdade e em algumas situações ainda são ignoradas pelos cientistas, de recentes pesquisas realizadas por etnoecólogos e etnobiólogos em comunidades tradicionais, que buscam o resgate e a valorização destes saberes, surgem a cada dia novas alternativas e reflexões que contrapõe os paradigmas vigentes e vem provocando efeitos positivos para o conhecimento científico. Nesta perspectiva, Dickmann e Dickmann (2008), sinalizam que o conhecimento científico é aquele estruturado, formulado e publicado na academia. Resultado, em sua maioria, de reflexões de lideranças oriundas da classe média que se dedicam curiosamente sobre as situações dos mais pobres com objetivo de analisá-las. Mesmo sendo uma forma particular de se caracterizar sob o ponto de vista classista da sociedade, não deixa de emitir um parecer sobre a diferenciação do senso comum e do científico.

Diante dos paradigmas interligados com o conhecimento científico emerge a figura do professor que protagoniza essa mudança de pensamento, quebrando os paradigmas que a muito tempo vêm se estabelecendo. Trata-se aqui da educação chamada de tradicional, onde a relação professor-aluno é marcada pelo autoritarismo do primeiro em relação ao segundo. Nesta perspectiva somente o professor possui conhecimento para ensinar, pois o papel do estudante é unicamente o de receber o conhecimento transmitido pelo professor, logo o silêncio em sala de aula é imposto pela autoridade docente.

\section{DESENVOLVIMENTO}

O paradigma é aquilo que as pessoas acreditam como verdade de uma prática baseada em suas realidades com ou sem experimentação científica. Moraes define o paradigma como uma "[...] constelação de concepções, valores, de percepções e de práticas compartilhadas por uma comunidade científica, que dá forma a uma visão particular da realidade, a qual constitui a base da maneira como a comunidade se organiza" (MORAES, 1996 apud BEHRENS, 2005, p. 26). 
Desta forma Moraes (apud BEHRENS, 2005) avalia o conceito de paradigma sobre uma estrutura de realidade social com a qual estabelece como verdades estabelecidas naquele determinado espaço-tempo.

De acordo com Kuhn (1991), os paradigmas são realizações científicas, que tem como objetivo fornecer problemas e soluções modelares para uma determinada comunidade praticante de uma ciência, sendo reconhecidos universalmente durante um período. A norma de paradigma surgiu das experiências de Kuhn (1978, p. 260), em que "[...] o conhecimento científico, assim como a linguagem, é intrinsecamente a propriedade comum de um grupo ou então não é nada". Entretanto para compreendê-lo é necessário conhecer o contexto-histórico dos grupos que o criam e o praticam. Kuhn estabelece uma forma interessante para o conceito de paradigma trazendo o conhecimento científico, mais elaborado, de um grupo social que traduz como um conjunto de verdades aceitas.

Segundo a interpretação de Morin (2000), vivemos uma época em que possuímos um velho paradigma e princípio que nos obriga a separar, simplificar, reduzir e formalizar, e que nos impede conceber a complexidades do real. Desta forma as percebe-se que as concepções sobre a verdade são protegidas por um compromisso pactuado por determinado grupo social.

Ainda nesta linha, Morin (2000) explica que os paradigmas são princípios de princípios, considerando-as como fundamentos mestres que controlam nossos espíritos e comandam teorias, inconscientemente.

Este modo de pensamento forja e faz acreditar em uma estrutura social administrada por um conjunto de verdades que norteiam a consciência e o espírito de convivência em sociedade.

Nesse sentido, Cortella (apud REVIDE, [S.d.], texto digital) afirma que em um mundo que passa por constante mudança, inclusive na área da crença de paradigmas, é necessário: "ensinar o que se sabe, praticar o que se ensina e perguntar o que se ignora". Além de que precisamos estar atento nas mudanças que ocorrem no mundo 
para saber quais acatar e rejeitar. Situação bem representativa do que rege o setor educacional, a base de uma educação, provocando profundas transformações e sinalizando uma ruptura do que é considerado senso comum e conhecimento científico, transformando paradigmas.

De acordo com estes conceitos acima e pela necessidade de novos paradigmas, os professores buscam inovações através de suas ações pedagógicas. A tarefa do professor já foi em algum tempo a de transmitir conhecimento, enquanto o aluno era submisso a essa situação, cuja abordagem tornava-se tradicional.

Os paradigmas conservadores concentravam-se em verdades impostas, conteúdos repassados, onde o aluno não tinha o poder de dar sua opinião. Esta prática trazia ao aluno uma capacidade decorativa, em que o ensino independia do aluno. Moraes (1997) já mencionava que o ensino é praticado através de aulas expositivas, introduzido de exercícios de leitura e cópias. E que baseado na eficácia e padronização, são estruturados com horários e currículos, rígidos e predeterminantes. Com alunos segregados por idade, em compartimentos organizado por fileiras, vivendo em um ambiente controlado com base única e indiferenciado.

$\mathrm{Na}$ ideia de vencer os paradigmas citados acima, surgem os Paradigmas Inovadores, onde os professores são desafiados a buscar novas práticas para exercer a docência. O aluno é visto como crítico e é envolvido com a produção do conhecimento; possui liberdade de pensamento. Ampliam-se as metodologias das aulas para pesquisa e formas inovadoras de promover a aprendizagem dos alunos. Cortella, bem orienta que a escola tem que estar apta a acompanhar as mudanças que ocorrem de forma simultânea. Isso pois nem tudo que vem do passado precisa se mantido no presente. A escola precisa saber distinguir aquilo que vem do passado e que pode ser levado a diante, em modo tradicional, daquilo que deve ser abandonado porque é arcaico.

Nesta análise de paradigmas duas vertentes aparecem, em que em uma, o professor é o centro da verdade num contexto conservador e em outra, porém, na abordagem humanista ele conduz a aprendizagem através de meios inovadores capazes de despertar curiosidade e motivação no aluno. Na metodologia tradicional, as aulas são 
expositivas e o aluno necessita ler e decorar os conteúdos trabalhados, enquanto na abordagem humanista são analisadas experiências e tomadas como discussões para aprendizado de forma inovadora, utilizando recursos e debates entre os grupos de alunos dentro da sala de aula, ou seja, o conhecimento é construído.

É necessário enfatizar uma educação dentro do contexto em que as crianças estão inseridas, para que haja significado e as relações de aprendizado sejam efetivas. Segundo Morin, sobre esse aprendizado, apresenta que o conhecimento é um refletor do mundo externo. "Todas as percepções são, ao mesmo tempo, traduções e reconstruções cerebrais com base em estímulos ou sinais captados e codificados pelos sentidos " (MORIN, 2000, p. 19-20).

Assim, é possível concordar que o conhecimento é fruto da interpretação que o ser humano faz sobre uma determinada realidade sob o seu ponto de vista, com alguma sistematização de ideias, desta forma entendendo um pouco mais o processo de produção de conhecimento por parte dos estudantes. Morin desenvolve teorias críticas criando ideias profundas:

Daí decorre a necessidade de destacar, em qualquer educação, as grandes interrogações sobre nossas possibilidades de conhecer. Pôr em prática estas interrogações constitui o oxigênio de qualquer proposta de conhecimento. [...] O conhecimento do conhecimento, que comporta a integração do conhecedor em seu conhecimento, deve ser, para a educação, um princípio e uma necessidade permanentes (MORIN, 2000, p. 29).

Considerando as abordagens mencionadas pelos autores citados de acordo com os conceitos de Paradigma e a influência no processo educativo, permitiu-se analisar criticamente cada conceito e perceber suas possíveis aplicabilidades em sala de aula. Neste sentido, entende-se que o Paradigma Inovador desafia os profissionais da educação a desenvolver um trabalho em equipe, pois no exercício da docência o professor precisa se manter na dinâmica de desenvolver ações que promovam a criticidade e reflexão pelos estudantes. 


\section{CONSIDERAÇÕES FINAIS}

Os paradigmas estão visíveis aos nossos olhos, enquanto profissionais da educação, ainda assim, alguns professores preferem continuar na zona de conforto, inertes quantos às transformações, no faz de conta de ensinar e aprender nas relações entre professor e estudante, ou seja, assume que tudo está perfeito e não é necessário mudar.

Diante de nossos paradigmas no decorrer do trabalho, hoje o nosso aluno quer aprender coisas além do que já está exposto no mundo externo, e isso exige do professor uma transformação de novas estratégias de ensino, para possibilitar novos horizontes de ensino e aprendizagem. Ouvimos nos bastidores da escola de nossos alunos que a escola "está chata", e nesta perspectiva o professor prefere fazer de conta que está tudo bem.

Levando em consideração essas reflexões, quebrar paradigmas já existentes exige do professor que seja protagonista das mudanças desde o planejamento até a sua execução.

Dito isto, é importante ressaltar que essas mudanças acontecem gradativamente, é necessário não apenas o professor se envolver no processo, mas que todos possam fazer parte deste processo bem como: a classe política, a família, e a sociedade em geral.

Estamos todos em direção de novos paradigmas que já é emergência e não mais uma necessidade, ou seja, a mudança precisa começar por nós, os professores, precisamos começar a fazer algo, desvendar o novo, através de pequenas atitudes, novas metodologias de ensino, atuando como investigadores de novos métodos que venham ao encontro das expectativas.

\section{REFERÊNCIAS}

ALVES, R. Filosofia da ciência: introdução ao jogo e suas regras. 10. ed. São Paulo, Loyola, 2005. 
BEHRENS, M. A. O paradigma emergente e a prática pedagógica. 2. ed. Petrópolis: Vozes, 2005.

CORTELLA, M. S. Educação, Escola e Docência - Novos Tempos, Novas Atitudes. São Paulo: Cortez, 2014.

DICKMANN, I; DICKMANN, I. Primeiras palavras em Paulo Freire. Passo Fundo: Battistel, 2008.

FOUCAULT, M. Microfísica do Poder. 9. ed. Rio de Janeiro: Graal, 1979.

KUHN, T. S. A estrutura das revoluções científicas. 2. ed. São Paulo: Perspectiva, 1978.

KUHN, T. S. A Estrutura das Revoluções Científicas. 12. ed. São Paulo: Perspectiva, 1991.

MORAES, M. C. O paradigma educacional emergente. Campinas: Papirus, 1997.

MORIN, E. Os sete saberes necessários à educação do Futuro. São Paulo: Cortez, 2000.

REVIDE. Cortella faz palestra em colégio de Ribeirão. [S.d.]. Disponível em: https://www.revide.com.br/editorias/gerais/cortella-faz-palestra-em-colegio-deribeirao/. Acesso em 10/04/2020.

Enviado: Julho, 2020.

Aprovado: Agosto, 2020. 